\title{
Atraumatic needles for lumbar puncture: why haven't neurologists changed?
}

\author{
A Davis, ${ }^{1,2}$ R Dobson, $^{1,3}{ }^{3}$ Kaninia, ${ }^{4}$ G Giovannoni, ${ }^{1,2}$ K Schmierer ${ }^{1,2}$
}

\begin{abstract}
'Department of Neurosciences, Blizard Institute, Barts and The London School of Medicine and Dentistry, Queen Mary University, London, UK ${ }^{2}$ The Royal London Hospital, CAG Neuroscience, Barts Health NHS Trust, London, UK

${ }^{3}$ Hurstwood Park Neurosciences Centre, Brighton and Sussex University Hospital Trust, Haywards Heath, West Sussex, UK

${ }^{4}$ The National Hospital for Neurology and Neurosurgery, UCLH NHS Foundation Trust, London, UK
\end{abstract}

\section{Correspondence to} Dr Angharad Grace Davis, Blizard Institute, Barts and The London School of Medicine and Dentistry, Queen Mary University, 4 Newark Street, London E1 2AT, UK; angharadgracedavis@gmail.com

Accepted 5 August 2015

To cite: Davis A, Dobson $R$, Kaninia S, et al. Pract Neurol Published Online First: [please include Day Month Year] doi:10.1136/practneurol2014-001055

\begin{abstract}
Diagnostic lumbar puncture is a key procedure in neurology; however, it is commonly complicated by post-lumbar puncture headache. Atraumatic needle systems can dramatically reduce the incidence of this iatrogenic complication. However, only a minority of neurologists use such needles. In this paper, we discuss possible reasons why neurologists have not switched to new technology, looking more at diffusion of innovation rather than lack of evidence. We suggest ways to overcome this failure to adopt change, ranging from local interventions to patient empowerment.
\end{abstract}

\section{THE CASE FOR ATRAUMATIC DIAGNOSTIC LUMBAR PUNCTURE}

Diagnostic lumbar puncture is a key procedure in neurology as well as other medical disciplines. Quincke carried out the first lumbar puncture in $1891 .{ }^{1}$ It is generally safe but a common complication is post-lumbar puncture headache syndrome ${ }^{2}$ caused by the iatrogenic cerebrospinal fluid (CSF) ${ }^{3}$ leak. The occurrence the headache syndrome depends largely on the type of needle used. Numerous studies have shown that frequency and severity of post-lumbar puncture headache syndrome can be dramatically reduced by replacing traumatic needles with atraumatic systems ${ }^{4}$ (figures 1 and 2). Using the $\mathrm{MeSH}$ (medical subject headings) terms 'lumbar puncture', 'headache', 'atraumatic' and 'spinal needle', we identified 11 studies that compared the incidence of postlumbar puncture headache following diagnostic lumbar puncture when using atraumatic versus traumatic spinal needles. All studies showed a lower incidence from using atraumatic spinal needles (table 1$).^{5-13}$

A meta-analysis of 38 studies across a wider population confirms a significantly lower rate of post-lumbar puncture headache. A subgroup analysis in the same study showed an even lower incidence of headache following atraumatic lumbar puncture in people undergoing the procedure for diagnosis rather than for anaesthesia. ${ }^{4}$ Earlier suggestions that atraumatic needles would have lower CSF flow rates and would impair pressure measurements have been invalidated. ${ }^{15}$ Finally, recent evidence confirmed the clinical effectiveness and the cost-effectiveness of switching to atraumatic spinal needles for diagnostic lumbar puncture. ${ }^{16}$

However, despite the overwhelming evidence favouring atraumatic (rather than traumatic) lumbar puncture, and practice guidelines from the American Academy of Neurology, ${ }^{17}$ neurologists around the world continue to dither about adopting this over 60-year-old 'innovation'. ${ }^{18} 19$ For example, a recent survey of UK neurologists showed that while $74 \%$ knew that atraumatic needles can significantly reduce the risk of postlumbar puncture headache syndrome, only $16 \%$ were actually using them. ${ }^{5}$ By contrast, anaesthetists consider the use of atraumatic needles to be the norm and continued use of traumatic needles to be ethically unacceptable. ${ }^{20}$

The question therefore arises: why are neurologists so reluctant to adopt atraumatic needles? We argue that the 'failure to switch' from one needle type to another has very little to do with the evidence, which is strikingly favours atraumatic needles. The explanation is more likely in the way that this innovation has been communicated-'diffused' as Everett Rogers ${ }^{21}$ calls it-among neurologists. We explore this hypothesis and propose suggestions on how to overcome this innovation deadlock. 


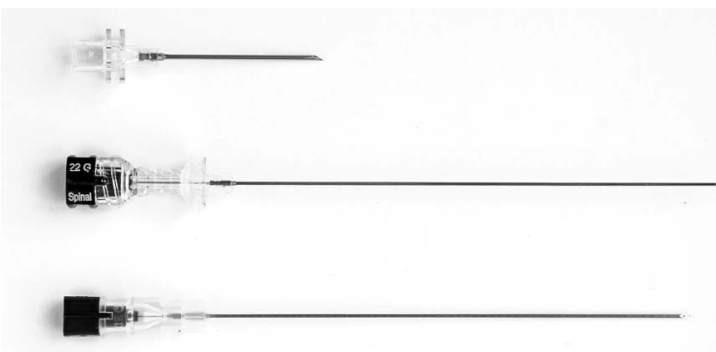

Figure 1 Overview of spinal needle types showing the atraumatic 'pinpoint' spinal needle (middle) with introducer (top), and traumatic 'cutting' spinal needle (bottom).

\section{RECOGNISING THE BENEFITS OF ATRAUMATIC LUMBAR PUNCTURE}

According to Rogers, for an innovation to be adopted, there must be a recognisable benefit. ${ }^{21}$ The nonadoption of atraumatic needle suggests a lack of awareness of the morbidity associated with post-lumbar puncture headache. The qualitative data support this impression, indicating that most UK neurologists believe that post-lumbar puncture headache occurs 'rarely'. This is also reflected in the wealth of patient information sheets that describe post-lumbar puncture headache as a rare and mild complication, despite the overwhelming evidence to the contrary. ${ }^{22-24}$ We propose a root cause of the discrepancy between evidence and awareness is the disconnect between those colleagues performing lumbar punctures and those who subsequently review patients with their postprocedure headache; the investigation is often performed in an outpatient or day-case setting, with patients leaving hospital soon afterwards. By the time they develop post-lumbar puncture headache, most

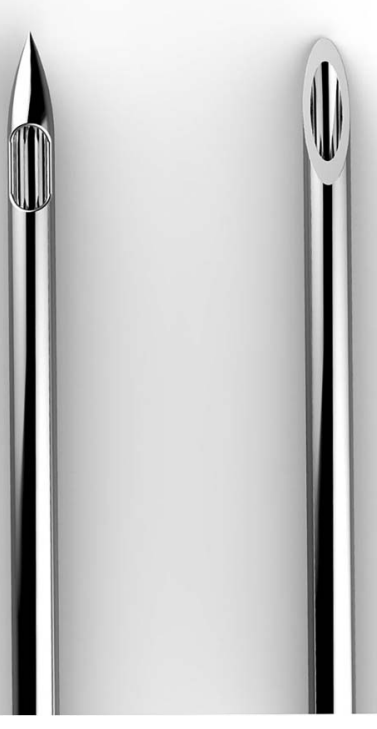

Figure 2 The needle tip in the atraumatic 'pinpoint' needle (left) and traumatic 'cutting' needle (right). have returned home and so present to their general practitioner rather than the hospital.

\section{MYTH-BUSTING: THE 'COMPLEXITY' OF ATRAUMATIC LUMBAR PUNCTURE}

The complexity of an innovation affects the likelihood of its adoption. ${ }^{21}$ There is a common perception among neurologists that using atraumatic lumbar puncture systems is more complex than using traumatic needles. ${ }^{5}$ However, the evidence suggests that the learning curve between atraumatic and traumatic lumbar puncture is no different. ${ }^{11}$ After completing a training session using a simulator, $92 \%$ of neurology residents indicated that they would use atraumatic needles again in their first lumbar puncture in a patient. ${ }^{25}$ Our group has shown no difference in the number of attempts using either needle system between two operators, one of whom had previously used only traumatic needles, while the other had used atraumatic needles from the outset. ${ }^{5}$

\section{AUSTERITY AND MULTI-PROFESSIONALISM IN PUBLIC HEALTHCARE AS BARRIERS TO CHANGE}

Financial pressures in public healthcare encourage us all to identify potential savings. Atraumatic needle systems cost three times as much as standard traumatic needles (in the UK, $£ 9.47$ vs $£ 3.42$ ). However, analysis of the total financial burden of diagnostic lumbar puncture-including the management of postlumbar puncture headache syndrome-shows that atraumatic systems are clearly more cost-effective. ${ }^{5} 16$ Doctors performing lumbar punctures may not know of the medical problems they may be causing, but commissioners should be more aware of the respective cost implications. However, with one needle type costing three times as much as the other, and with savings on the total cost of the procedure either not assessed or not obvious, a narrow hospital-focussed financial view continues to determine which needle type to purchase. The result is the oft-quoted 'unavailability' of atraumatic needles on hospital wards and in clinics. ${ }^{5}$

\section{BOUNDARIES BETWEEN CLINICAL COMMUNITIES AS BARRIERS TO CHANGE}

We also need to consider how the evidence for atraumatic needles is communicated among neurologists, particularly compared with anaesthetists, where their use is standard. It was an anaesthetist who published the first study in Anaesthesiology in 1949, showing a reduction incidence of headache following use of atraumatic needles. ${ }^{26}$ There has since been a wealth of evidence in both neurological and anaesthetic journals. ${ }^{2-13} \quad 26-31$ Rogers describes how 'heterophilous communities' (eg, neurologists and anaesthetists), show slower rates of adoption than those where innovators and early adopters share the same role as those they subsequently influence. ${ }^{21}$ This may 
Table 1 Studies comparing incidence of post-lumbar puncture headache when using atraumatic and traumatic needles

\begin{tabular}{|c|c|c|c|}
\hline Reference & Patient group & Study type & $\begin{array}{l}\text { Incidence of post-lumbar } \\
\text { puncture headache }\end{array}$ \\
\hline Braune and Huffman ${ }^{6}$ & $n=75$ & Prospective, double-blind clinical trial & $\begin{array}{l}\text { Traumatic needle } 36 \% \\
\text { atraumatic needle } 4 \%\end{array}$ \\
\hline Kleyweg et al ${ }^{7}$ & $\begin{array}{l}\mathrm{n}=99 \text { traumatic needle }=50 \\
\text { atraumatic needle }=49\end{array}$ & Double-blind randomised trial & $\begin{array}{l}\text { Traumatic needle } 32 \% \\
\text { atraumatic needle } 6 \%, p=0.001\end{array}$ \\
\hline Strupp et $a l^{8}$ & $\begin{array}{l}\mathrm{n}=230 \text { traumatic needle }=115 \\
\text { atraumatic needle }=115\end{array}$ & Prospective, randomised, double-blind study & $\begin{array}{l}\text { Traumatic needle } 24.4 \% \\
\text { atraumatic needle } 12.2 \%, p<0.05\end{array}$ \\
\hline Torbati et $a \rho^{9}$ & $\begin{array}{l}\mathrm{n}=317 \text { traumatic needle }=54.6 \% \\
\text { atraumatic needle }=45.4 \%\end{array}$ & Retrospective review & $\begin{array}{l}\text { Traumatic needle } 11.32 \% \\
\text { atraumatic needle } 4.48 \%, p=0.017\end{array}$ \\
\hline Luostarinen et $a l^{10}$ & $\begin{array}{l}\mathrm{n}=78 \text { traumatic needle }=39 \\
\text { atraumatic needle }=39\end{array}$ & Prospective, randomised study & $\begin{array}{l}\text { Traumatic needle } 49 \% \\
\text { atraumatic needle }=36 \% \text {, not significant }\end{array}$ \\
\hline Vakharia and Lote ${ }^{11}$ & $\begin{array}{l}\mathrm{n}=52 \text { traumatic needle }=24 \\
\text { atraumatic needle }=36\end{array}$ & $\begin{array}{l}\text { Retrospective (traumatic needle) and } \\
\text { prospective (atraumatic needle) }\end{array}$ & $\begin{array}{l}\text { Traumatic needle } 10 \% \\
\text { atraumatic needle } 8 \%, p<0.01\end{array}$ \\
\hline Jager et $a l^{12}$ & Atraumatic needle $=600$ & Prospective & Atraumatic needle $3.6 \%$ \\
\hline Hammond et $a l^{13}$ & $\begin{array}{l}\mathrm{n}=187 \text { traumatic needle }=130 \\
\text { atraumatic needle }=57\end{array}$ & Prospective & $\begin{array}{l}\text { Traumatic needle } 32 \% \\
\text { atraumatic needle } 19 \%\end{array}$ \\
\hline Thomas et $a l^{14}$ & $\begin{array}{l}\mathrm{n}=97 \text { traumatic needle }=48 \\
\text { atraumatic needle }=49\end{array}$ & Double-blind randomised trial & $\begin{array}{l}\text { Risk of headache with atraumatic needle } \\
\text { reduced by } 26 \% \text { ( } 95 \% \mathrm{Cl} 6 \% \text { to } 45 \%)\end{array}$ \\
\hline Lavi et al $\left.\right|^{2}$ & $\begin{array}{l}\mathrm{n}=55 \text { traumatic needle }=26 \\
\text { atraumatic needle }=29\end{array}$ & Prospective, randomised trial & $\begin{array}{l}\text { Traumatic needle } 36 \% \\
\text { atraumatic needle } 3 \%, p=0.002\end{array}$ \\
\hline Davis et $a l^{5}$ & $\begin{array}{l}\mathrm{n}=96 \text { traumatic needle }=48 \\
\text { atraumatic needle }=48\end{array}$ & Prospective observational study & $\begin{array}{l}\text { Traumatic needle } 50 \% \\
\text { atraumatic needle } 20.9 \%, p=0.01\end{array}$ \\
\hline
\end{tabular}

This excludes studies of children and patients undergoing either therapeutic lumbar puncture or epidural anaesthesia.

explain the difference between specialities. Even when excluding the interspeciality lag between anaesthetists and neurologists, the adoption rate of atraumatic needles still appears to be much slower among neurologists. $518 \quad 32-34$

\section{DIFFERENCES IN MEDICAL PRACTICE AND TRAINING AS BARRIERS TO CHANGE}

The dissemination of evidence to underpin changes in clinical practice does not rely on peer-reviewed publications and on communication and training among colleagues within a speciality. The procedure-based nature of anaesthetics with its emphasis on 'elbow-to-elbow' training may well have facilitated the diffusion and adoption of atraumatic needles. Rogers suggests the rate of adoption within a community follows a bell-shaped curve. If the cumulative number of adopters is plotted, the result is an S-shaped curve. This S-shaped curve rises slowly at first, when there are only a few adopters in each time period, but then accelerates before eventually levelling out to a 'tipping point' in adoption. Rogers outlines adopter categories and describes progression along the curve as depending on dissemination of information and practice across these categories, within which individuals possess a different threshold for innovation. ${ }^{21}$ Others have argued that dissemination within healthcare systems takes less of a linear format. ${ }^{35}$ Are anaesthetists more venturesome than neurologists, or does the nature of the speciality where procedural proficiency forms a critical part of training account for this difference?

\section{MAKING DIAGNOSTIC LUMBAR PUNCTURES FINALLY ATRAUMATIC: SUGGESTIONS TO OVERCOME BARRIERS}

The common denominator of the barriers to switch from traumatic to atraumatic diagnostic lumbar puncture as standard in neurology is a distinct lack of communication. Doctors need to know the evidence and act on it. To act they need to be trained in atraumatic lumbar puncture, and pass their knowledge and skill on to trainees, and perhaps to some seniors too. Commissioners need to be aware of the real cost of lumbar puncture, and neurologists should actively engage in translating the evidence in favour of atraumatic needles. Where traumatic needles are still used,

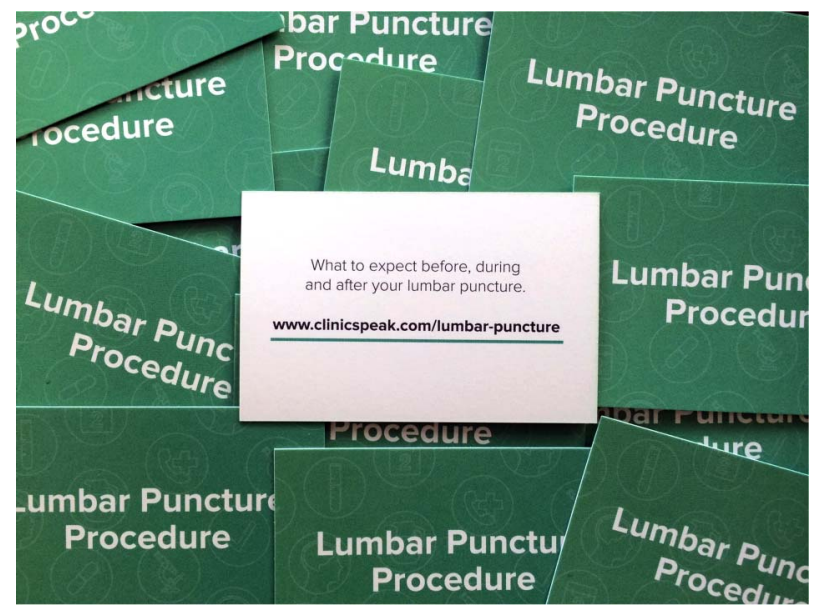

Figure 3 Patient information cards with the ClinicSpeak weblink, for patients awaiting diagnostic lumbar puncture. We can provide a sample pack of these cards on request. 
and commissioners need 'local' evidence to convince them, audits comparing the two needle systems can provide the required information.

Finally, patients should be encouraged to seek information and to choose the needle type for their lumbar puncture. The 'clean hands campaign' of the National Patient Safety Agency tried to reassure patients; 'it's $\mathrm{OK}$ to ask' clinicians to wash their hands. ${ }^{36}$ This could serve as a model for patients to request an atraumatic needle for their lumbar puncture. We have developed a simple web-based tool for patients to read before their lumbar puncture, including information about the benefits of atraumatic needle for their lumbar puncture: http://www. clinicspeak.com/LumbarPuncture/ (figure 3).

\section{Key points}

- There is overwhelming evidence to support the use of atraumatic needles to reduce complications in diagnostic lumbar puncture; despite this, few neurologists have adopted this 60-year-old 'innovation'.

- Potential barriers to adoption include the communication of the evidence to commissioners who may not appreciate the overall cost savings; clinicians have a responsibility to ensure that those who procure our medical equipment know the evidence surrounding it.

- Lack of training opportunities may account for the perceived technical difficulties oft-quoted by neurologists resisting 'making the switch'; sharing good practice and communicating between neurology and anaesthetics-where atraumatic needles are standard - should help training and adoption.

- The patient champion has a role in influencing change of practice; a web-based information resource http://www.clinicspeak.com/LumbarPuncture/ encourages patients to ask about spinal needle type.

Twitter Follow Klaus Schmierer at @KlausSchmierer

Acknowledgements Images courtesy of 'Agency of Design'. Contributors $\mathrm{AD}$ and $\mathrm{SK}$ performed the literature review described in the review. AD drafted the manuscript, which was subsequently edited by RD, GG and KS. All authors agreed on the final submitted manuscript.

Competing interests GG has received research grant support from Bayer-Schering Healthcare, Biogen-Idec, GW Pharma, Merck Serono, Merz, Novartis, Teva and Sanofi-Aventis. GG has received personal compensation for participating on Advisory Boards in relation to clinical trial design, trial steering committees and data and safety monitoring committees from Bayer-Schering Healthcare, Biogen-Idec, Eisai, Elan, Fiveprime, Genzyme, Genentech, GlaxoSmithKline, Ironwood, Merck-Serono, Novartis, Pfizer, Roche, Sanofi-Aventis, Synthon BV, Teva, UCB Pharma and Vertex Pharmaceuticals. KS is a principal investigator of trials sponsored by Novartis and Roche. He has received speaking honoraria from, and served on advisory boards for, Novartis, Merck-Serono and Merck Inc.
Provenance and peer review Not commissioned; externally peer reviewed. This paper was reviewed by Brendan McLean, Truro, UK.

\section{REFERENCES}

1 Calthorpe N. The history of spinal needles. Anaesthesia 2004;59:1231-41.

2 Lavi R, Yarnitsky D, Rowe JM, et al. Standard vs atraumatic Whitacre needle for diagnostic lumbar puncture: a randomized trial. Neurology 2006;67:1492-4.

3 Bezov D, Lipton RB, Ashina S. Post-dural puncture headache: Part I. Diagnosis, epidemiology, etiology and pathophysiology. Headache 2010;50:1144-52.

4 Demaerschalk BM, Wingerchuk DM. Atraumatic dural puncture needles for preventing post-dural puncture headache: meta-analysis of randomized controlled trials. Neurology 2002;58(Suppl 3):A285-6.

5 Davis A, Dobson R, Kaninia S, et al. Change practice now! Using atraumatic needles to prevent post lumbar puncture headache. Eur J Neurol 2014;21:305-11.

6 Braune HJ, Huffman GA. A prospective double-blind clinical trial, comparing the sharp Quinke needle $(22 \mathrm{G})$ with an "atraumatic" needle $(22 \mathrm{G})$ in the introduction of post-lumbar puncture headache. Acta Neu Scand 1992;86:50-4.

7 Kleyweg RP, Hertzberger LI, Carbaat PA. Significant reduction in post lumbar puncture headache using an atraumatic needle. A double-blind, controlled clinical trial. Cephalalgia 1998;18:635-7.

8 Strupp M, Schueler O, Straube A, et al. "Atraumatic Sprotte needle reduces the incidence of post-lumbar puncture headaches. Neurology 2001;57:2310-12.

9 Torbati S, Katz D, Silka P, et al. 234: Comparison of blunt versus sharp spinal needles used in the emergency department in rates of post-lumbar puncture headache. Ann Emerg Med 2009;54:S73.

10 Luostarinen L, Heinonen T, Luostarinen M, et al. Diagnostic lumbar puncture. Comparative study between 22-guage pencil point and sharp bevel needle. J Headache Pain 2005;6:400-4.

11 Vakharia VN, Lote H. Introduction of Sprotte needles to a single-centre acute neurology service: before and after study. JRSM Short Rep 2012:3;82.

12 Jager H, Krane M, Schimrigk K. [Lumbar puncture-the post-puncture syndrome. Prevention with an "atraumatic" puncture needle. Clinical observations]. Schweiz Med Wochenschr 1993;123:1985-90.

13 Hammond ER, Wang Z, Bhulani N, et al. Needle type and the risk of post-lumbar puncture headache in the outpatient neurology clinic. J Neurol Sci 2011;306:24-8.

14 Thomas SR, Jamieson DR, Muir KW. Randomised controlled trial of atraumatic versus standard needles for diagnostic lumbar puncture. BMJ 2000;321:986-90.

15 Pelzer N, Vandersteene J, Bekooij T, et al. Are atraumatic spinal needles as efficient as traumatic needles for lumbar puncture? Neurol Sci 2014;35:1997-9.

16 Tung CE, So YT, Lansberg MG. Cost comparison between the atraumatic and cutting lumbar puncture needles. Neurology 2012:78;109-13.

17 Armon C, Evans RW. Addendum to assessment: prevention of post-lumbar puncture headaches. Neurology 2005;65:510-12.

18 Stendell L, Fomsgaard JS, Olsen KS. There is room for improvement in the prevention and treatment of headache after lumbar puncture. Dan Med J 2012;59:A4483. 
19 Adrendt K, Demaerschalk BM, Wingerchuk DM, et al. Atraumatic lumbar puncture needles: after all these years, are we still missing the point? Neurologist 2009;15:17-20.

20 Heard CM, Fletcher JE. Is it ethically correct to study the Quincke spinal needle in obstetric patients? Anesth Analg 2002;94:233-4.

21 Rogers EM. 1995. Diffusion of innovations. New York: Free Press.

22 http://www.nia.nih.gov/sites/default/files/lp_participant handout.pdf

23 http://www.wwl.nhs.uk/Library/All_New_PI_Docs/Audio_ Leaflets/General/Lumbar_Puncture/Lumbar_Puncture.pdf

24 http://www.health.qld.gov.au/consent/documents/medicine_01. $\mathrm{pdf}$

25 Tung C. Residents' adoption of the atraumatic lumbar puncture needle. Neurology 2013:80;180-2.

26 Barker P. Headache after dural puncture. Anaesthesia 1989;44:696-7.

27 Haraldson S. Headache after spinal anesthesia: experiments with a new spinal needle. Anesthesiology 1951;12:321-7.

28 Flaatten H, Krakene J, Vedeler C. Post-dural puncture related complications after diagnostic lumbar puncture, myelography and spinal anaesthesia. Acta Neurol Scand 1998;98:445-51.
29 Lavi R, Rowe JM, Avivi I. Traumatic vs. atraumatic 22 G needle for therapeutic and diagnostic lumbar puncture in the hematologic patient: a prospective clinical trial. Haematologica 2007;92:1007-8.

30 Hart JR, Whitacre RJ. Pencil point needle in prevention of postspinal headache. J Am Med Assoc 1951;147:657-8.

31 Broadley SA, Fuller GN. Audit of lumbar puncture practice in United Kingdom neurology centres. J Neurol Neurosurg Psychiatry 1997;63:266.

32 Plumer MH, Rottman R. How anesthesiologists practice obstetric anesthesia: responses of practicing obstetric anesthesiologists at the 1993 meeting of the Society for Obstetric Anesthesia and Perinatology. Reg Anesth 1996;21:49-60.

33 Salzer J, Sundström P, Vågberg M, et al. Lumbar puncture preferences among Swedish neurologists. Neurol Res 2015;37:92-4.

34 Birnbach DJ, Kuroda MM, Sternman D, et al. Use of atraumatic spinal needles among neurologists in the United States. Headache 2001;41:385-90.

35 Greenhalgh T, Robert G, Macfarlane F, et al. Diffusion of innovations in service organisations: Systematic review and recommendations. Milbank Q 2004;82:581-629.

36 NPSA clean your hands campaign: http://www.npsa.nhs.uk/ cleanyourhands/ 